\title{
Uma aplicação da Análise Biomecânica no Processo de Montagem de Produtos Industriais
}

\author{
Ricardo M. Naveiro \\ D.Sc. Escola de Engenharia e COPPE/UFRJ , Universidade Federal do Rio de Janeiro \\ Cx. Postal 68507 - Cep. 21945-970 \\ E-mail: ricardo@pep.ufrj.br \\ Carla P. Guimarães \\ Doutoranda da COPPE/UFRJ, Pesquisadora do Instituto \\ Nacional de Tecnologia, Av. Venezuela, 82, DvDI, Centro, RJ \\ E-mail: cpguimas@aol.com
}

\begin{abstract}
Resumo
\section{Palavras-chave}

Processos de montagem, Avaliação biomecânica, Indústria biomédica.
\end{abstract}

Este trabalho apresenta um método informatizado de avaliação biomecânica e sua aplicação na avaliação do trabalho de montagem de componentes numa indústria do setor biomédico. O método envolve a utilização da técnica da videocinematografia para aquisição de imagens, sua digitalização e seu posterior tratamento através do programa BIOMEC. O programa BIOMEC dispõe de uma base de dados em biomecânica e antropometria e de procedimentos de cálculo que permitem determinar com precisão os níveis de sobrecarga estática e dinâmica apresentados nas situações filmadas. 0 estudo efetuado com funcionárias que trabalham na montagem de equipamentos biomédicos mostrou a eficácia do método como alternativa a métodos qualitativos de análise de risco baseados em observação direta.

\section{Biomechanical Analysis of Assembly Process of Manufacturing Products}

\begin{abstract}
This paper describes a computer-assisted method for biomechanics evaluation and its application to the analysis of assembly work in a biomedical industry. The method involves the use of the video cinematography technique for image capturing followed by a digitalisation process that enables the BIOMEC program treat images. The program BIOMEC encompasses an anthropometric and a biomechanics database and calculation procedures that allow to define with precision the muscle-skeletal overload in the studied situations. The case study conducted with the assembly workers of a biomedical industry showed the method efficacy as an alternative to qualitative methods based in direct observation.
\end{abstract}

Key words

Assembly work, Biomechanics evaluation, Biomedical industry. 


\section{INTRODUĈ̣̃O}

Os processos de montagem respondem por cerca de 50 até $70 \%$ dos custos de mão-de-obra de um produto. Tratase, portanto, do processo que envolve o maior contingente de pessoas em uma indústria de manufatura e o responsável pela maior parcela do custo total de fabricação. Nos últimos anos vêm sendo empreendidos esforços para reduzir os custos de montagem através da utilização da automação; entretanto, a maioria das operações de montagem continua sendo feita com praticamente as mesmas ferramentas utilizadas no passado. Os ciclos de trabalho de montagem são em sua maioria curtos: 1,5 minuto para $42 \%$ dos postos de trabalho e menos de 30 seg para $26 \%$ dos postos de trabalho, o que acarreta muitas operações repetidas e lesões por esforço repetido são comuns de ocorrer entre os trabalhadores (NAVEIRO, 2001).

$\mathrm{O}$ percentual da força de trabalho industrial envolvida em tarefas de montagem é enorme. O quadro a seguir mostra dados de empresas européias referentes ao final da década de 1980.

Esses dados mudaram bastante na década de $1990 \mathrm{em}$ função da eletronificação dos produtos, o que resultou em produtos com menor número de componentes e, por conseguinte, com um menor número de operações de montagem, porém, de qualquer forma, as operações de montagem ainda respondem pela maior parcela do custo de mão-de-obra de fabricação. No Japão, a indústria eletroeletrônica é a que mais utiliza robôs para operações de montagem (NAVEIRO, 2001).

\section{MÉTODOS E SISTEMAS DE MONTAGEM}

Os vários métodos de montagem podem ser grupados em três categorias: montagem manual, montagem mecanizada e montagem robotizada. A escolha do método de montagem para um novo produto vai depender de uma série de fatores:

- ciclo de vida previsto para o produto;

- custo e disponibilidade de mão-de-obra;

- volume de produção;

- variedade dos produtos;

- tamanho do lote;

- flexibilidade.
A montagem manual utiliza ferramentas de baixo custo e dispositivos de armazenagem de peças também de baixo custo. Ela é empregada quando se quer flexibilidade alta associada a uma grande variedade de produtos. Seus custos permanecem relativamente constantes e independentes do volume de produção.

A montagem mecanizada se aplica aos casos em que existem grandes volumes de produção e baixa variedade. São equipamentos especialmente projetados para montar um determinado produto, consistindo de cabeçotes de montagem associados a equipamentos periféricos de alimentação e orientação. São, portanto, equipamentos de automação rígida, com ciclos fixos de operação de custo relativamente alto, sem possibilidade de reconversão para outros produtos.

A montagem robotizada se aplica a situações intermediárias nas quais existem lotes médios de produção e variedade média de produtos.

O Gráfico 1 demonstra o campo de aplicação de cada tipo de sistema.

Na prática, o que se encontra é uma combinação desses métodos, como, por exemplo, um posto de montagem manual associado a um equipamento automático para orientação das peças, ou uma linha de montagem robotizada associada a postos de trabalho manuais, como ocorre na indústria automobilística.

Para a escolha de um sistema de montagem devem ser considerados três fatores preliminarmente: o volume de produção, o número de peças e o tempo de retorno do investimento. Produtos cuja concepção e processo de montagem foram otimizados para se adequarem à montagem robotizada apresentam bom rendimento em processos de montagem manual.

Para análise e projeto de um sistema de montagem há que se considerar as operações elementares realizadas para se efetuar o trabalho. As operações de montagem podem ser subdivididas em uma série de tarefas encadeadas, tais como posicionamento, transporte, etc., de tal forma que, para cada tipo de operação, pode ser desenvolvido um equipamento específico. As principais operações de montagem são as seguintes:

- Armazenagem - disposição das peças a serem montadas.

- Posicionamento - orientação do componente em relação ao outro.

\begin{tabular}{|l|c}
\hline Máquinas-ferramenta & 55,0 \\
\hline Equipamentos agrícolas & 20,1 \\
\hline Eletrodomésticos & 32,0 \\
\hline Veículos automotores & 45,6 \\
\hline
\end{tabular}


- Transporte - deslocamento do componente, envolvendo movimentação, separação, conjunção, etc.

- Orientação - direcionamento do componente para a montagem.

- Inserção - posicionamento do componente em relação ao outro.

As peças sujeitas a montagem manual apresentam determinadas características que podem facilitar ou dificultar sua montagem. São características associadas à geometria e às condições apresentadas pelas peças no momento da montagem. Os principais parâmetros que interferem no processo de montagem manual são os seguintes:

- Possibilidades de manipulação - peças escorregadias, peças que se enroscam, peças afiadas, etc.

- Necessidade de orientação - peças não simétricas com dificuldades de se colocar na posição correta.

- Direções e sentidos de montagem - numero de direções de montagem.
- Dificuldades de inserção - dificuldades relacionadas a restrições de visibilidade, por dificuldade de acesso, etc.

- Necessidade de ferramentas especiais para manipulação - peças pesadas, peças cuja montagem está fora do alcance do montador.

Esses parâmetros estão diretamente relacionados com problemas ergonômicos decorrentes de um posto de trabalho mal projetado para a atividade a ser desenvolvida, portanto, devem ser levados em conta no momento do projeto do produto. É na fase de concepção que se definem a forma geométrica detalhada de cada componente e a sua forma de fixação em relação aos outros.

\section{PROCESSOS DE MONTAGEM MANUAL E DORT}

Algumas estatísticas vêm indicando os DORT - Distúrbios Osteomusculares Relacionados ao Trabalho

Gráfico1: Classificação de Sistemas de Montagem (Naveiro, 2001).

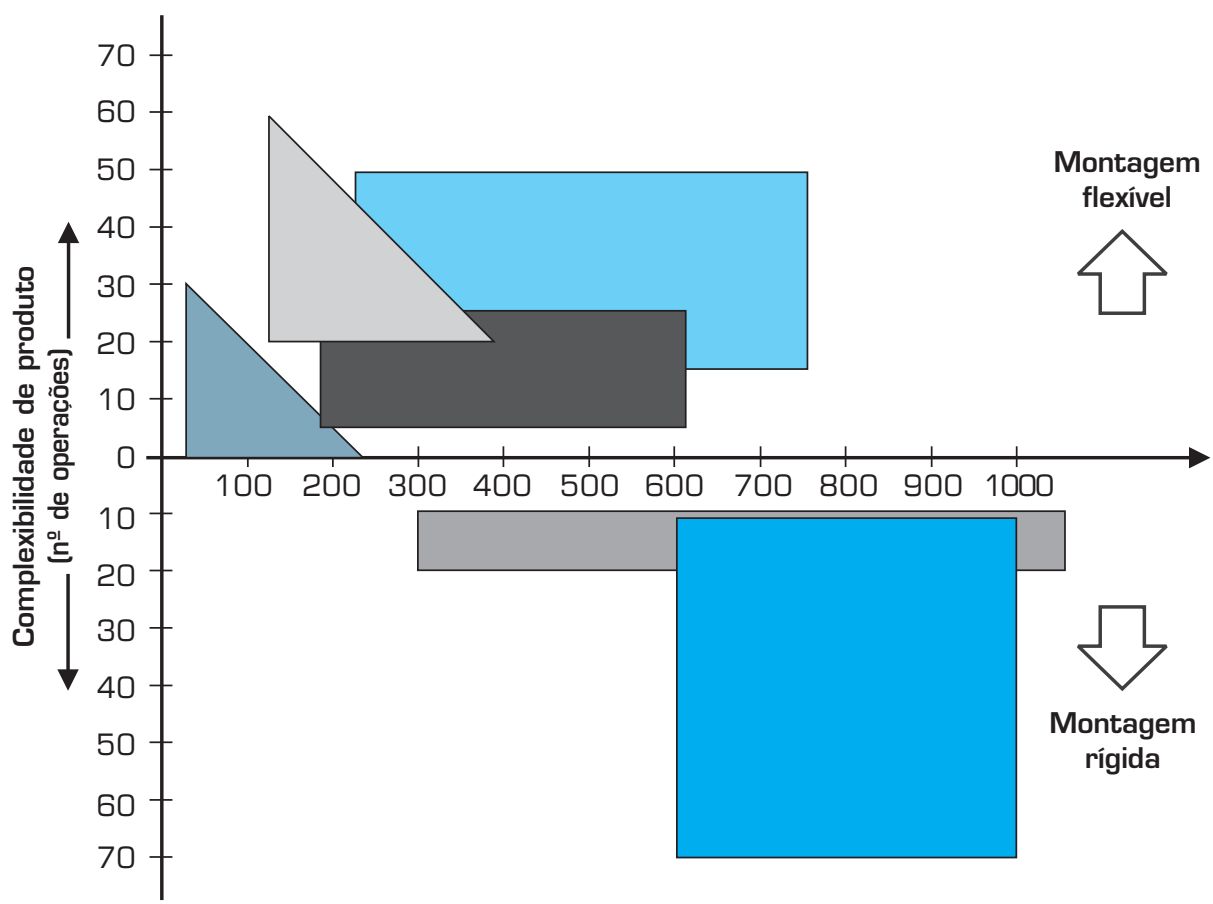

Linhas montagem com transporte automático de peças

Máquinas automáticas de montagem [rígida]

Linhas automáticas de montagem (rígida)

Estação de montagem manual

Linhas flexíveis de montagem

Células flexíveis de montagem 
(nova denominação da LER) - como uma das maiores preocupações das indústrias, em função de sua alta incidência. Dados fornecidos pelo relatório anual de 1995 (NUSAT/MG - Núcleo de Saúde do Trabalhador de Minas Gerais), apontam os DORT como a doença ocupacional que ocupou o primeiro lugar em número de atendimentos no ano de 1995 (70,6\% do total de atendimentos (LIMA, 1998). A OSHA. "The U.S - Occupational Safety and Health Administration" - reconhece os DORT como um problema sério de saúde, responsável por $56 \%$ das doenças do trabalho e mais do que $33 \%$ de todos os custos de compensação trabalhistas. Em países como Suécia, Dinamarca, Noruega e Finlândia, problemas de saúde ocupacional relacionados aos DORT representam um custo total de 3 a $5 \%$ do Produto Interno Bruto desses países. (WINKEL and WESTGAARD, 1996).

O processo de montagem de produtos é causa potencial dos DORT em função dos movimentos repetidos presentes nesse tipo de tarefa. Alguns tipos de DORT mais comuns em atividade de montagem manual são os seguintes (Figura 1):

1. Tendinite - Inflamação aguda ou crônica dos tendões. Manifesta-se com mais freqüência nos músculos flexores dos dedos, e geralmente é provocada por dois fatores; movimentação frequiente e período de repouso insuficiente.

2. Tenossinovite - Inflamação aguda ou crônica das bainhas dos tendões. Assim como a tendinite, os dois principais fatores causadores da lesão são: movimentação freqüente e período de repouso insuficiente. A doença manifesta-se principalmente através de dor na região, que é agravada por movimentos voluntários. Associados à dor, manifestam-se também edema e crepitação na região.

3. Síndrome do Túnel do Carpo - Compressão do nervo mediano no túnel do carpo. As causas mais comuns deste tipo de lesão são: a exigência de flexão do punho, a extensão do punho e a tenossinovite ao nível do tendão dos flexores - neste caso, os tendões inflamados levam a uma compressão crônica e intermitente da estrutura mais sensível do conjunto que compõe o túnel do carpo: o nervo mediano.

4. Síndrome de Quervain - Constrição dolorosa da bainha comum dos tendões do longo abdutor do polegar e do extensor curto do polegar. Estes dois tendões têm uma característica anatômica interessante: correm dentro da mesma bainha; quando friccionados, costu-

Figura 1: Localização de alguns exemplos de DORT no corpo humano (adaptado HAGBERG, 1995).

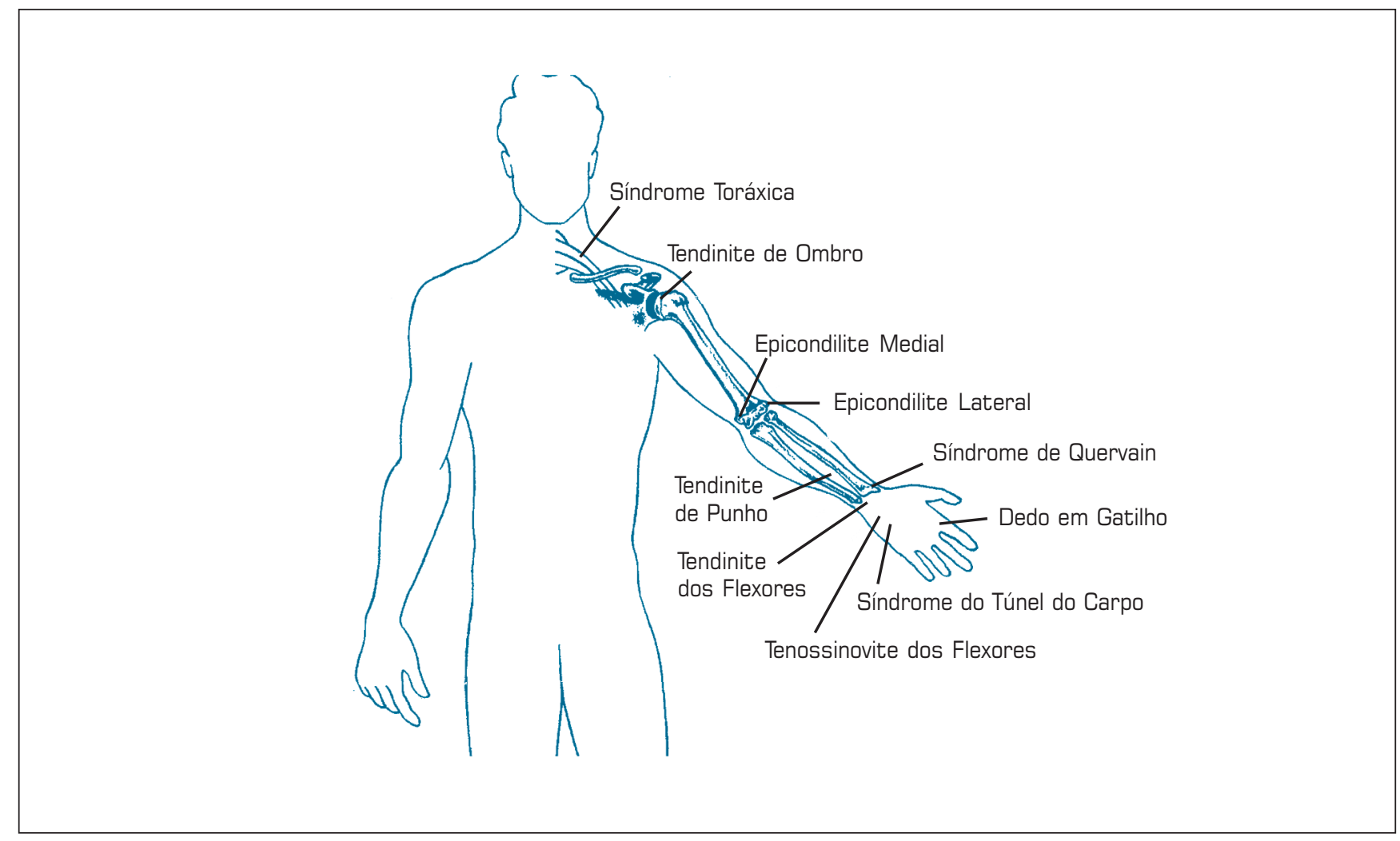


mam se inflamar. O principal sintoma é a dor muito forte no dorso do polegar. Um dos principais fatores causadores deste tipo de lesão está no ato de fazer força torcendo o punho.

Dos levantamentos realizados em diferentes estudos, alguns fatores de risco foram relatados como mais freqüentes para o desenvolvimento dos DORT nos membros superiores. Tais fatores estão relacionados tanto aos parâmetros físicos do posto de trabalho quanto a questões organizacionais. Podemos citar, entre outros, a postura de trabalho, a freqüência de manuseio, a duração do trabalho e a pausa para descanso. Forças aplicadas, cargas estáticas, velocidade e aceleração dos movimentos são considerados como fatores biomecânicos de risco. Além desses, existem também fatores psicológicos - a habilidade na execução da tarefa, experiência, capacidade de aprendizado -, assim como fatores ambientais tais como vibração e temperatura.

A contribuição específica de cada fator de risco para os DORT ainda é desconhecida (KRUIZINGA, 1998), assim como também não há uma definição dos níveis quantitativos aceitáveis para esses fatores de risco (SCHOENMARKLIN, 1994).

Essa pluralidade de fatores de risco torna-se um complicador para o profissional envolvido no estudo das etiologias que levam ao aparecimento dos DORT, uma vez que certas síndromes apresentam uma sintomatologia muito semelhante. Alguns métodos têm sido criados para tentar analisar esses fatores, tanto de forma qualitativa como quantitativa, mas ainda existe uma carência de métodos práticos, quantitativos e padronizados para detecção desses fatores de risco. (KILBON, 1988, WINKEL and WESTGAARD, 1992, SILVERSTEIN, 1997).

\section{SISTEMAS DE AVALIAC̣ÃO DE RISCOS}

Os métodos ergonômicos de análise do trabalho utilizam a observação das atividades laborais de forma a identificar variáveis ergonômicas associadas às causas de prejuízo à saúde do trabalhador. Normalmente, essas metodologias de levantamento e análise se utilizam inicialmente de listas de verificação. Essas listas permitem também comparar a situação do trabalhador antes e depois da intervenção ergonômica ter sido feita no posto de trabalho. Podem-se citar, entre outros, o método RULA - "The Rapid Upper Limb Assessment" (MCTAMNEY and CORLETT, 1993), o método PLIBEL - 'Method for the Identification of Musculoskeletal stress which may have injurious effects" (KEMMLERT,1995), e o Índice de Deformação - "Strain Index" (GARG and MOORE, 1997).
Uma análise desses métodos de observação mostra que eles foram desenvolvidos para atender diferentes propósitos, e conseqüentemente diferem em muitos aspectos. (KILBOM, 1994b). Alguns métodos foram desenvolvidos para a análise das situações de trabalho que podem acarretar sobrecarga biomecânica ou fisiológica especificamente para as estruturas e segmentos dos membros superiores. Nesses, as avaliações biomecânicas se concentram em três fatores principais: força, repetição e postura. Mas existem outros modelos de risco que são baseados em quatro fatores: repetição, força, postura e ausência de recuperação. (DRURY, 1987; PUTZ and ANDERSSON,1988)

Existem também modelos conceituais para algumas patologias específicas dos membros superiores tais como a Síndrome do Túnel do Carpo. Nesses modelos, o limite de exposição foi determinado pela repetição do movimento, pela força requerida e pelo desvio postural do punho, articulação envolvida neste caso. A descrição completa desses estudos se encontra em Winkel and Westegaard (1992) e em Tanaka and McGlotin (1993).

A intervenção ergonômica para a melhoria das condições de trabalho aplica as diferentes metodologias acima descritas visando modificar as atividades de trabalho ou o ambiente de trabalho, incluindo-se aí o layout do posto de trabalho, as ferramentas de trabalho, e até mesmo a organização do trabalho, de forma a manter a atividade laboral dentro da capacidade e das limitações dos indivíduos que a executam.

A prevenção foi e continua sendo a melhor forma de combate aos diversos tipos de patologias do trabalho. A adoção de posturas e ritmos de trabalho mais adequados, associados às pausas ao longo da jornada de trabalho, a adequação do produto às condições do trabalhador e o dimensionamento adequado dos postos de trabalho são as principais medidas para a prevenção de doenças como os DORT, e para evitar o afastamento do trabalho.

Porém, em certos casos, quando não é possível resolver os problemas ergonômicos no momento do projeto do produto, ou através da adequação do posto de trabalho, é necessário partir para a automação do processo de montagem em substituição ao processo manual.

O objetivo deste artigo é apresentar um estudo da montagem de produtos industriais do ponto de vista dos riscos biomecânicos causados ao trabalhador. Esse estudo faz uso de um sistema de videocinematografia que foi desenvolvido para fornecer dados que permitem a análise quantitativa dos parâmetros biomecânicos (cinemáticos e cinéticos) envolvidos nas tarefas de montagem. 


\section{SISTEMA BIOMEC}

O sistema BIOMEC de videocinematografia é parte integrante da tese de D.Sc. de um dos autores deste artigo e está sendo aperfeiçoado à medida que novas necessidades são colocadas pela sua utilização.

O sistema BIOMEC (Figura 2) é um conjunto de softwares que possibilitam a análise cinemática do movimento humano a partir da digitalização de imagens de trabalho capturadas por câmeras VHS. A partir das imagens digitalizadas é possível a superposição de modelos biomecânicos sobre as mesmas, de forma a permitir o cálculo das sobrecargas internas nas diferentes estruturas do aparelho locomotor. Os resultados obtidos pela superposição permitem a análise de alguns fatores de risco tais como postura, freqüência de manuseio, velocidade e aceleração dos movimentos, assim como possibilitam inferir sobre a relação desses fatores com as sobrecargas internas na estrutura locomotora. A partir desses primeiros resultados é possível prever situações de incidência dos DORT em trabalhos de montagem manuais. A Figura 2 apresenta um esquema geral da seqüência de atividades realizadas com o BIOMEC.

O BIOMEC incorpora os seguintes aspectos: definição do modelo espacial, definição das variáveis cinemáticas, definição e seleção dos modelos biomecânicos, definição da frequiência de captura dos dados e questões técnicas tais como a razão de aspecto e os fatores de escala.
O modelo espacial é uma representação esquemática do corpo humano, ou da parte dele que se quer analisar. Marcas anatômicas correspondentes ao modelo espacial escolhido são colocadas nas pessoas de forma a definir os segmentos corporais que serão analisados. Cada segmento é tratado pelo BIOMEC como um vetor orientado, de forma a possibilitar os diversos cálculos angulares e de deslocamento. Um modelo biomecânico pode ser associado a uma postura de trabalho em estudo, de forma a permitir estimar as sobrecargas articulares, os ângulos articulares e segmentares, assim como suas derivações: velocidades e acelerações angulares (parâmetros cinemáticos).

O procedimento de trabalho consiste em duas etapas complementares:

- Etapa de aquisição dos dados;

- Etapa de processamento dos dados.

A etapa de aquisição dos dados consiste no planejamento e na definição dos parâmetros das filmagens dos movimentos na situação de trabalho real. Dependendo do número de planos de movimento a serem filmados, são utilizadas uma, duas ou três câmeras. As câmeras trabalham sincronizadas e devem estar posicionadas aproximadamente em ângulo reto, e centradas num mesmo ponto. Elas também devem obedecer a um certo afastamento do objeto filmado, de forma a evitar os erros de paralaxe. A Figura 3 mostra a tela principal do sistema BIOMEC com o modelo espacial dos membros superio-

Figura 2: Esquema geral do BIOMEC.

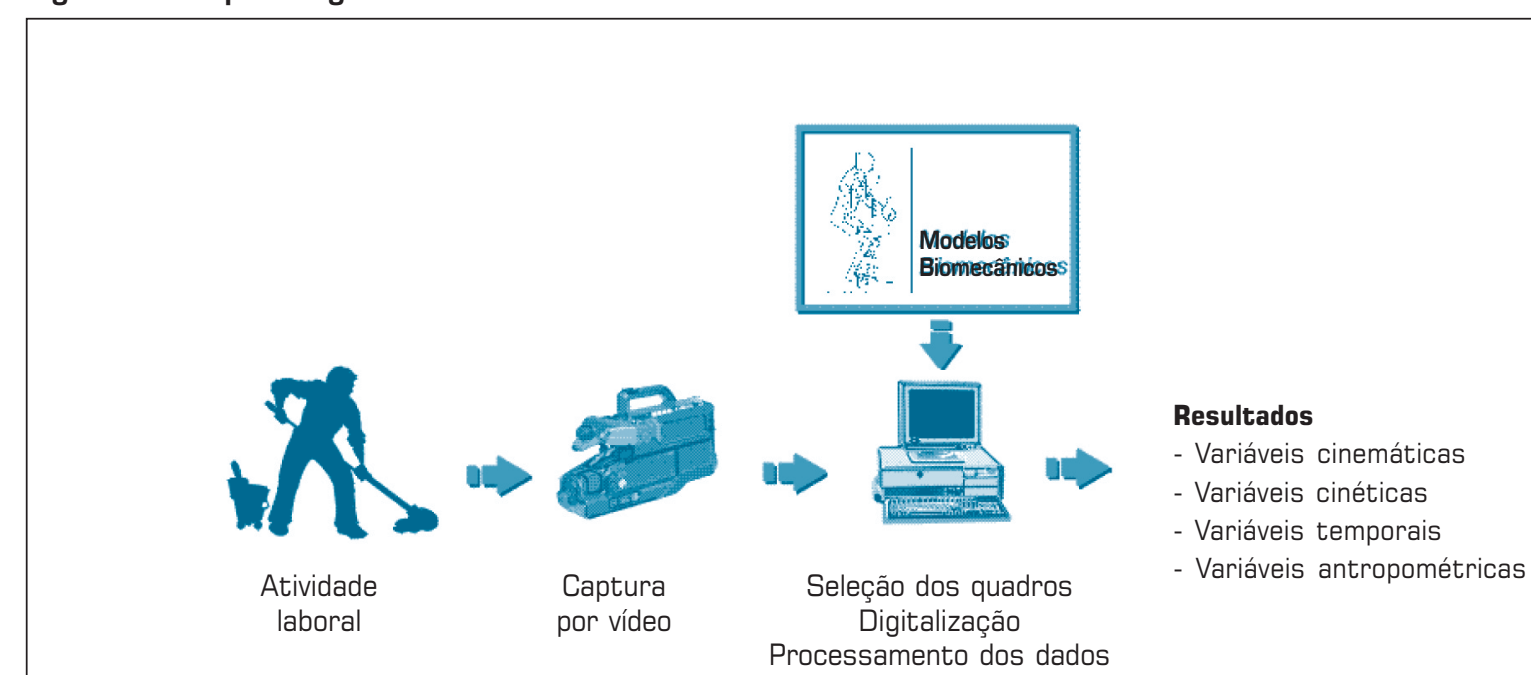

BIOMEC 
res associado a filmagem de uma operação de montagem.

A freqüência de captura dos dados, razão de aspecto e fator de escala são parâmetros da filmagem e do equipamento (filmadora) usado que permitiram calcular os parâmetros temporais - duração das fases definidas no estudo e freqüência de manuseio, por exemplo. A razão de aspecto corrige as distorções fornecidas pela câmera filmadora, e o fator de escala nos permite calcular os valores reais de comprimento, a partir da imagem filmada.

Na preparação do ambiente de filmagem, temos que posicionar marcas visíveis em pontos anatômicos específicos do corpo (pontos articulares) que definiram o comprimento do segmento corporal e uma marcação extra de comprimento conhecido deve estar visível para se definir o fator de escala.

Após a filmagem, entramos na etapa do tratamento e processamento das imagens pelo sistema. Inicia-se pela seleção dos quadros, que definem a seqüência do movimento que será analisada quadro a quadro, bem como a sua freqüência de captura - a freqüência máxima é de 30 quadros/segundo. Nessa etapa utilizamos o software Adobe Premiere 5.5, e as imagens selecionadas são convertidas em arquivo de imagem (. avi) para posterior digitalização.

$\mathrm{Na}$ fase de digitalização, a tela do computador se converte em um mapa de bits onde cada ponto é arrastado até a marca do segmento corporal filmado. Uma malha de ligação entre os pontos é disponibilizada de forma a diminuir o erro decorrente de posicionamento.

$\mathrm{O}$ processo de filtragem permite que as coordenadas digitalizadas sejam corrigidas e homogeneizadas através de funções matemáticas que corrigem os sinais indesejáveis (ruídos) presentes. As Figuras 4 e 5 mostram a imagem digitalizada e a tela referente à filtragem de sinais.

\section{ESTUDO DE CASO}

A empresa escolhida para aplicação do BIOMEC foi um fabricante de produtos biomédicos localizado no Estado do Rio de Janeiro. O trabalho foi realizado como parte de um convênio de cooperação existente entre o Programa de Engenharia de Produção da COPPE/ UFRJ e a referida indústria.

O experimento foi desenvolvido conforme as etapas descritas a seguir:

- Etapa preliminar - levantamento de dados preliminares para seleção do produto e dos postos de trabalho que seriam analisados.

- Etapa de levantamento - aplicação do sistema de videocinematografia BIOMEC na análise da atividade laboral selecionada. Constituiu-se de uma etapa piloto para ajustes da filmagem e de uma etapa final com a filmagem de operárias na situação real de trabalho.

- Etapa de processamento e análise feitos através da utilização do software BIOMEC já descrito.

A primeira etapa foi de sensibilização, os funcionários receberam informações básicas sobre ergonomia e sobre os objetivos e importância do experimento. Em seguida, foram visitados os setores de RH, Departamento Médico e Setor de controle de qualidade para verificar que setores da fábrica apresentavam maiores índices de afastamento do trabalho por DORT e quais produtos apresentavam maiores índices de perdas e erros de montagem. Foi pesquisado também quais os setores onde ocorriam perdas da funcionalidade, isto é, onde as trabalhadoras não conseguiam retornar ao posto de trabalho original após o afastamento.

O setor com maior número de problemas foi o de "Montagem de Equipamentos de Infusão", parte integrante da fábrica de equipamentos médicos da empresa com cerca de $26,5 \%$ de casos de DORT comprovados. Esse setor faz parte da Fábrica de Equipamentos Médicos de Produtos de Infusão. Essa fábrica tem cerca de 600 funcionários, sendo que $70 \%$ do efetivo são mulheres, que trabalham em diferentes tarefas, desde a injeção de plásticos até a embalagem final do produto, incluindo-se aí as diversas tarefas de montagem manual.

O aparecimento de DORT no setor de montagem não está restrito às funcionárias de um determinado turno apenas; todos os três turnos (manhã, tarde e noite) já apresentaram casos de afastamentos por DORT. Na maioria dos casos, as funcionárias, ao serem liberadas pelo setor médico para retornarem ao serviço, não puderam retornar a esse setor e foram direcionadas para trabalhar em outros setores, como pré-montagem, injeção, etc.

Foram realizadas palestras para os funcionários desse setor específico nos três turnos, com o objetivo de apresentar o trabalho a ser realizado na empresa e os benefícios que os resultados do trabalho poderiam trazer para o coletivo. Isso se deu inicialmente com entrevistas com os supervisores das áreas, que lidam diretamente com as funcionárias no seu dia-a-dia, conhecem a produção exigida e o desempenho de cada uma.

Filmagens preliminares foram realizadas para aprofundar o conhecimento das seqüências de movimentos que as funcionárias executavam em suas atividades de montagem. As filmagens ocorreram nos diferentes turnos. Foram selecionadas para cada turno cerca de seis funcionárias de diferentes percentis antropométricos e 
que apresentavam diferentes níveis de produtividade (os dados foram fornecidos pelos supervisores da área em cada horário). Elas eram filmadas em seus postos de

Figura 3: Módulo I: Tela Principal - entrada do programa e preparação para análise dos dados.

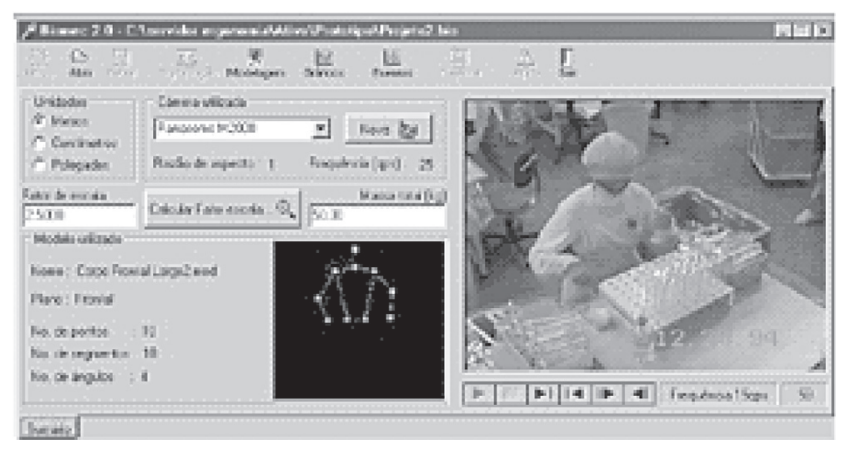

Figura 4: Telas de digitalização.

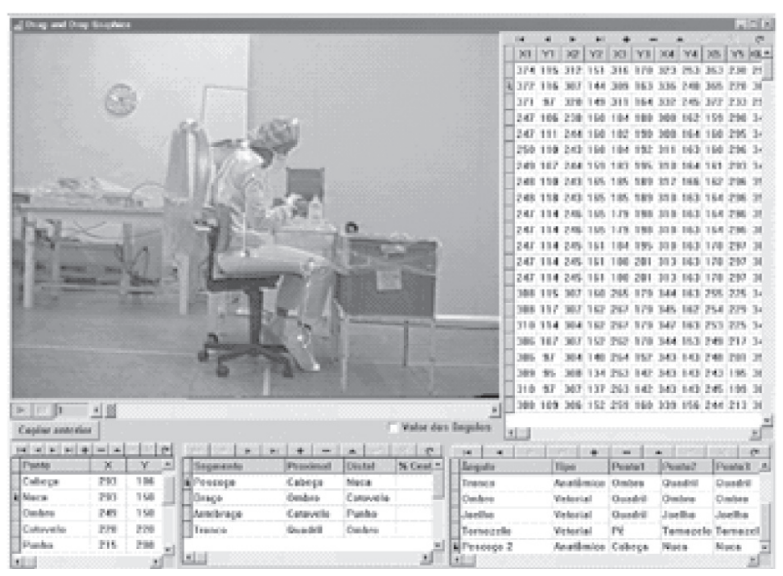

trabalho, de hora em hora, registrando-se todas as seqüências de movimento. Após a seleção das funcionárias, e antes da filmagem, elas eram chamadas para uma entrevista na qual era explicado como se daria a filmagem e qual a sua importância para o estudo. Nesse momento também era solicitado o consentimento da funcionária para ser filmada.

Durante a filmagem (a cada 1 hora) era apresentado à funcionária um esquema de figuras de todo o corpo, membros superiores e mãos em destaque para que elas pudessem indicar as regiões de desconforto. Esse procedimento foi idêntico ao sugerido por Hedge (1999), em seu estudo sobre desconforto nos membros superior em trabalhadoras realizando operações de montagem. Após as filmagens, as funcionárias eram convidadas a participar, em outro horário, de uma entrevista com a pesquisadora para verem o filme e com isso fornecerem esclarecimentos sobre o que estava sendo

Figura 5: Tela de filtragem dos dados.

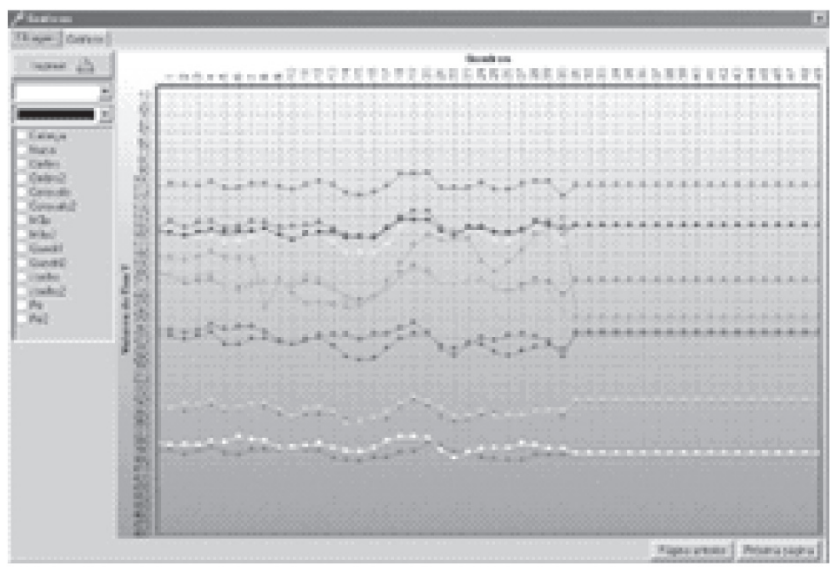

Figura 5: Esquema explicativo dos módulos de aquisição e processamento do BIOMEC.

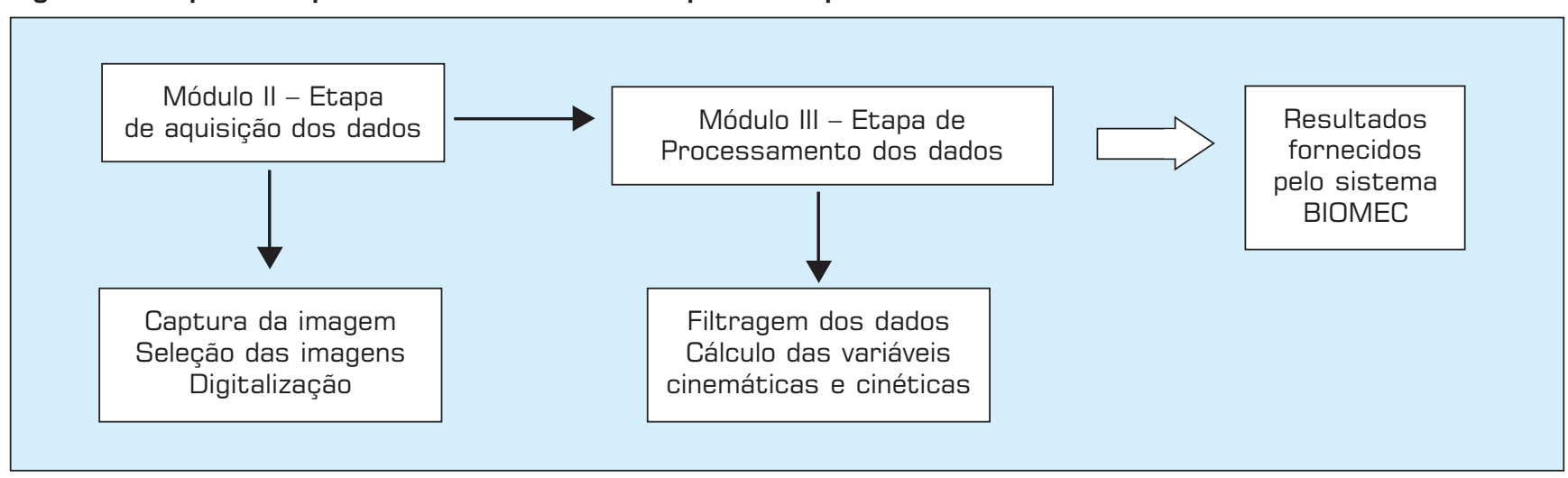


realizado, como executavam a tarefa e por que faziam daquela maneira.

Foram também programadas entrevistas com as funcionárias que já tinham apresentado sintomas de DORT, mesmo as que não trabalhavam mais no setor de montagem em infusão. Nas entrevistas foram apresentadas algumas filmagens com determinados produtos, já pontuados pelas outras funcionárias (da ativa) como sendo os de maior dificuldade para montagem. Das informações desse segundo grupo de funcionárias foi possível identificar quais tipos de movimentos e quais tipos de equipos lhes causavam maior desconforto e dores nas regiões afetadas.

Após esse levantamento inicial, foram selecionados os produtos para filmagem e análise biomecânica. Os produtos selecionados foram: intrafix com injetor lateral intrafix padrão, conforme ilustrado na Figura 6.

Estes produtos apresentam o seguinte fluxograma de montagem: posicionamento da pinça, inserção do flashball ou do injetor lateral, inserção do intermediário, inserção da câmera e cintagem ou embalagem. Cabe salientar que este fluxograma não é fixo, pois a funcionária pode modificá-lo ao longo da jornada de trabalho.

A etapa de levantamento consistiu numa etapa-piloto para testar o aparato técnico de filmagem, composta de uma série de verificações, tais como: visibilidade, nitidez, planos de tomada de cena, ajuste da posição das câmeras, etc. A etapa-piloto se iniciou com a seleção do local para a filmagem. Foram testados vários locais, de forma que o local escolhido reproduzisse o máximo possível as condições encontradas no ambiente real de trabalho. Foi selecionada, então, uma sala utilizada para montagem de um outro equipo, que apresentava uma grande similaridade com a situação real de trabalho, e para lá foi deslocado um posto de trabalho completo da montagem em infusão. As filmagens abrangeriam os três planos de movimento: sagital, frontal e transversal.

Para a filmagem transversal (visão de cima) foi confeccionado um tubo de sustentação para a câmera transversal, que ficou $2 \mathrm{~m}$ acima do posto filmado. Com um goniômetro de plástico foi medida sua perpendicularidade com o teto, e com o auxílio de um tirante foi

Figura 6: Desenho esquemático dos equipos selecionados.
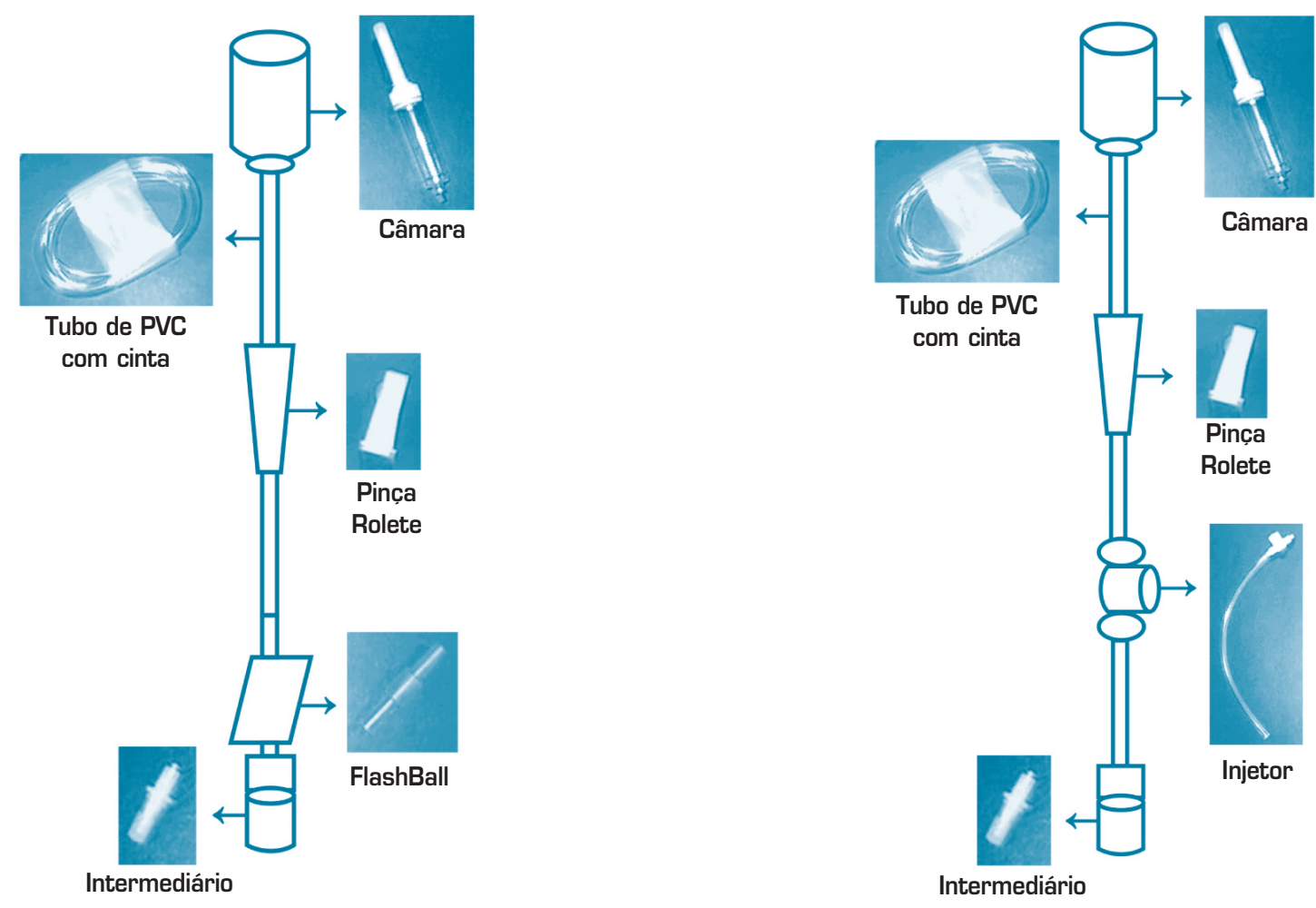
projetada a sua direção sobre o solo, de forma a garantir a perpendicularidade com as outras câmeras e com o posto de trabalho. As demais câmeras foram então posicionadas perpendicularmente a essa câmera (localizada próximo ao teto) com o auxílio de marcas diretivas traçadas sobre o solo. As câmeras foram também niveladas com o solo, com auxílio de um nível de bolha. As câmeras foram posicionadas nas seguintes direções com o posto de trabalho: visão sagital direita $(3,50 \mathrm{~m})$, visão sagital esquerda $(3,60 \mathrm{~m})$, e visão frontal posterior $(3,40$ $\mathrm{m})$. A visão sagital foi subdividida, pois os movimentos do membro superior direito e esquerdo eram diferenciados durante as montagens. A Figura 7 mostra o esquema montado para a realização das filmagens.

Foram confeccionadas e testadas marcas globulares de diferentes tonalidades e tamanhos. As marcas, inicialmente de cor preta, tiveram problemas de visualização quando confrontadas com o fundo. Foram então pintadas de cor mais clara, cor que proporcionasse maior contraste com o ambiente de filmagem. A cor vermelha fluorescente foi escolhida uma vez que contrastou mais com o ambiente e com a roupa das funcionárias.

Marcas do punho tiveram que ser colocadas nas operárias com auxílio de um elástico, pois devido a movimentação mais intensa desse segmento durante o trabalho, elas caíam com facilidade. Inicialmente foram usadas marcas de diâmetro menor para o punho, mas depois foram substituídas pelas de tamanho igual às demais, pois apresentavam uma melhor visualização. Foi confeccionada uma marca dupla para ser colocada na região da sétima cervical, para caracterizar a região do pescoço.

Também foram testadas marcas de referência sobre a mesa de trabalho em todos os planos de filmagem (sagital, frontal e transversal), abarcando no mínimo três pontos ortogonais. Com isso e com o referencial de comprimento (fator de escala) poderíamos confirmar e corrigir a perpendicularidade das câmeras com o posto de trabalho, comparando o ângulo filmado com o medido.

A etapa final do levantamento consistiu num experimento controlado com uma amostra de funcionárias pertencentes aos diversos percentis antropométricos. Para essa etapa do experimento foram selecionadas funcionárias que atendessem os seguintes requisitos: não apresentassem problemas de DORT, atingissem normalmente a produção estabelecida para os equipamentos selecionados para teste, e que pertencessem à classe dos percentis 5 e 95 do sexo feminino em altura sentada (ERGOKIT/1998). Foram selecionadas pelo menos duas funcionárias por turno (manhã e tarde).

$\mathrm{O}$ único ajuste permitido pelo posto de trabalho era o

Figura 7: Posicionamento das câmeras para a filmagem final.

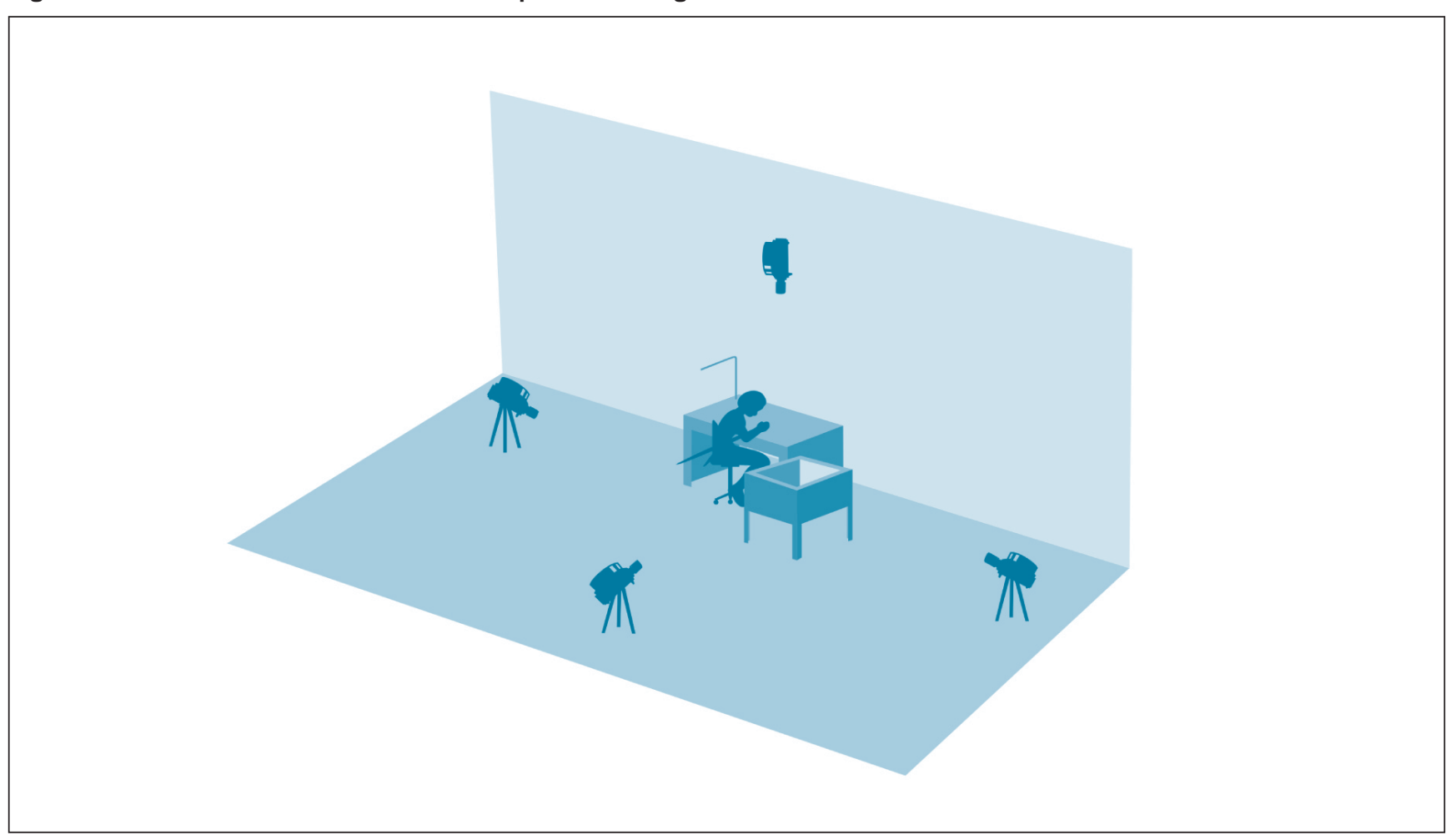


ajuste na altura da cadeira, pois esse é o único elemento do posto que apresenta regulagem. Os demais elementos eram similares para todas as funcionárias selecionadas. Foi estipulado, a partir da produção média do semestre da funcionária, o número de equipos que deveriam ser montados em uma hora. Esse procedimento foi realizado para cada equipo selecionado, uma vez que eles apresentavam quantidades de produção diária diferente.

$\mathrm{O}$ ambiente de filmagem era preparado para cada sessão seguindo os passos anteriormente descritos para a etapa piloto. Para cada funcionária era estipulado um horário de apresentação de acordo com seu turno de trabalho. Elas eram previamente preparadas para a filmagem. No dia da filmagem a funcionária trabalharia com a montagem do mesmo equipo até a hora de ser chamada para participar do experimento. No primeiro turno, a filmagem transcorria após o intervalo, às $11 \mathrm{~h} 00$ da manhã. No segundo turno a filmagem transcorria antes do intervalo, por volta das $17 \mathrm{~h} 00$. Foi mantida uma mesma carga de trabalho precedente ao experimento para ambos os grupos.

Após estarem preparadas para a filmagem, as funcionárias se posicionavam para iniciar a montagem. Era dado a cada uma um tempo de 15 minutos para adaptação ao novo local de montagem. Após esse período inicia-se a filmagem real.

É necessário enfatizar que todo o experimento realizado foi testado na fase piloto e discussões com as funcionárias foram realizadas nas entrevistas, quanto aos limites estabelecidos pelas diversas condições de filmagem propostas. Essas discussões proporcionaram informações quanto ao melhor horário de coleta (horário de pico) e quanto às diferenças que poderiam aparecer pelas condições apresentadas.

\section{ANÁLISES E CONCLUSÕES}

Uma das limitações ocorridas nessa análise foi a im-

\section{A MULHER PERCENTIL 5}

Tabela 1: Posturas no plano sagital.

\begin{tabular}{|l|l|l|}
\hline SEGMENTOS CORPORAIS & \multicolumn{1}{|c|}{ POSTURA ASSUMIDA } & \multicolumn{1}{c|}{ ATIVIDADES } \\
\hline Cabeça & $41^{\circ}$ a $75^{\circ}$ & Toda seqüência de montagem \\
\hline Tronco & $78^{\circ}$ com eixo $X$ e $31^{\circ}$ com Y & Movimentação de objetos distantes e sustentação \\
\hline Ombro direito & $86^{\circ}$ a $105^{\circ}$ & Movimentação de objetos distantes \\
\hline Ombro esquerdo & $0^{\circ}$ & $\begin{array}{l}\text { Sustentação, variação na hora de movimentar: pegar o } \\
\text { feixe de tubos para o cintamento }\end{array}$ \\
\hline Cotovelo direito & $62^{\circ}$ a $74^{\circ}$ & Sustentação \\
\hline
\end{tabular}

Figura 8: Inserindo a pinça no tubo.

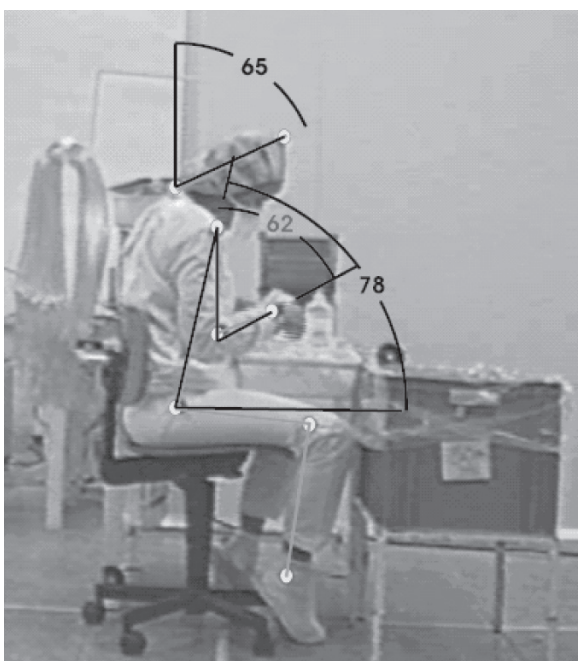

Figura 9: Colando e inserindo o intermediário.

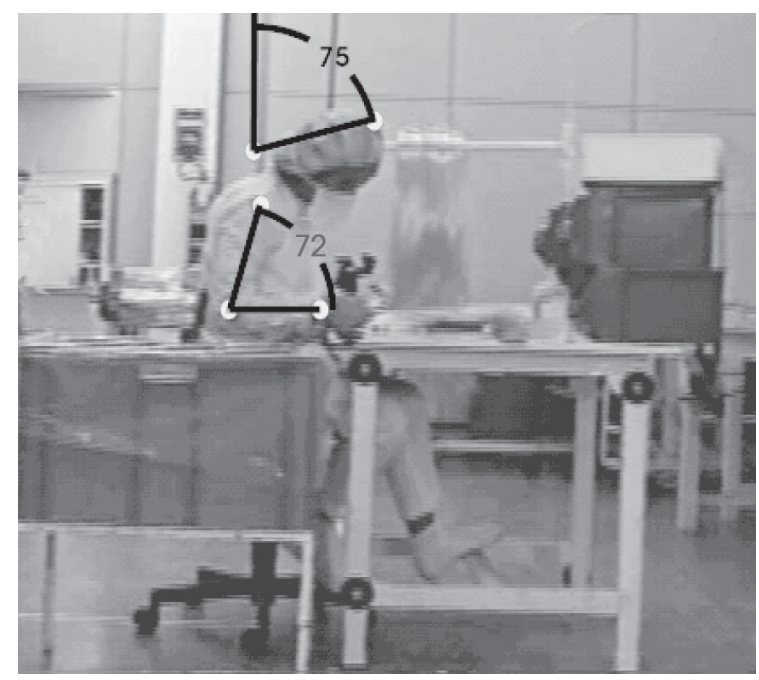


Figura 10: Movimentação de caixa com as pinças.

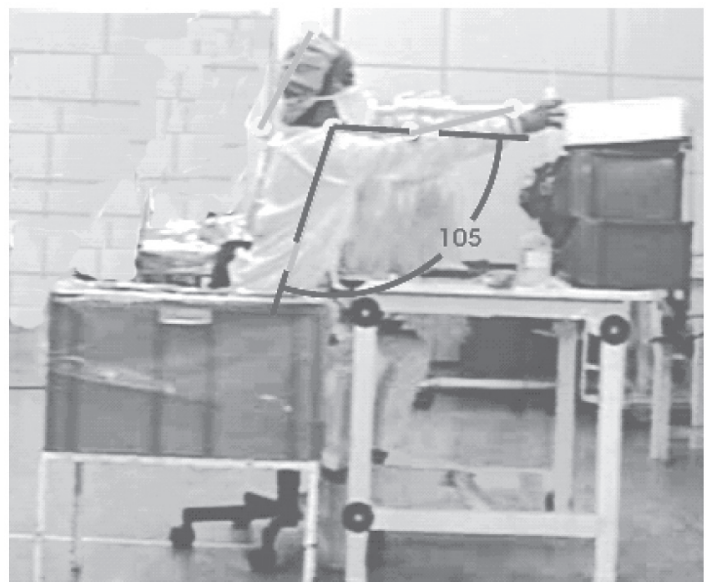

possibilidade de visualização do punho e das mãos. A filmadora usada não tinha velocidade suficiente para acompanhar a grande velocidade de movimentação desses segmentos e a visão de filmagem das câmeras era bloqueada, na maioria das vezes, por outras partes corporais ou mesmo por partes do posto de trabalho. Tentou-se filmar mais próximo, mas a velocidade de movimentação não deixava o filme nítido o suficiente para essa análise. Não foram então calculados os valores de velocidade angular e aceleração angular que se desejava para o movimento das mãos e do punho. Apenas valores angulares para as partes do corpo que pouco se movimentavam ou permaneciam em postura estática prolongada foram calculados.

As seqüências de movimento foram selecionadas com base nos resultados das entrevistas realizadas na etapa preliminar, nas quais as funcionárias indicavam quais as maiores dificuldades no processo de montagem e as posturas que mais incomodavam e causavam desconforto.

Os resultados fornecidos pelo sistema BIOMEC serão apresentados na forma de tabelas e caracterizam as posturas que representavam riscos para incidência dos DORT e as atividades desenvolvidas. A título de exem-
Figura 11: Movimentação dos tubos para ensacar.

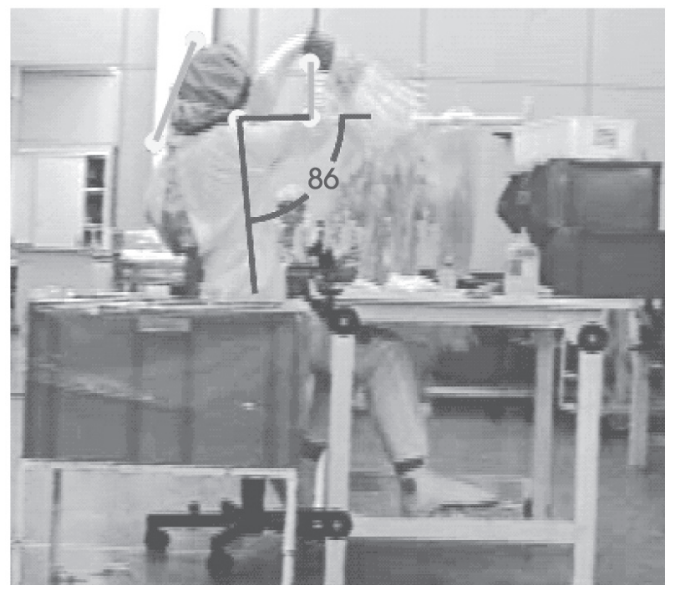

Figura 12: Movimentação e posicionamento da cinta para ensacar.

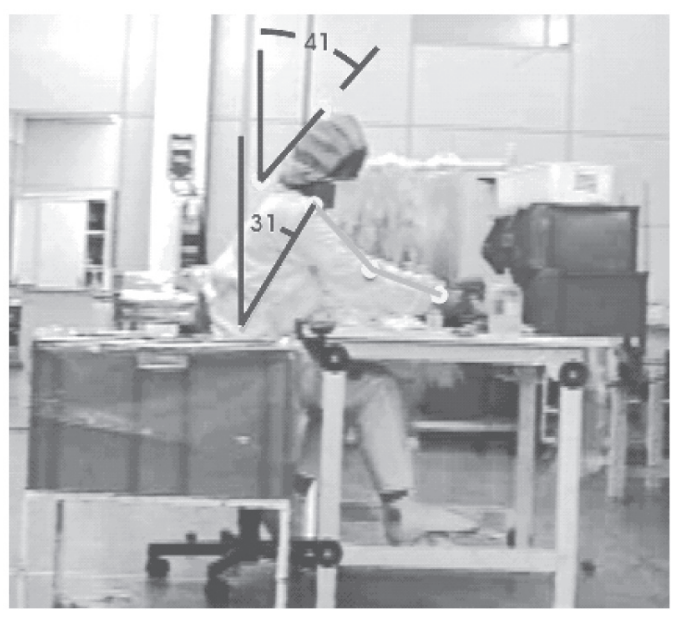

plo serão apresentados a seguir os resultados referentes à análise da mulher percentil 5 .

A mulher percentil 95 também foi analisada e apresentou resultados muito semelhantes à mulher percentil 5. A diferença mais marcante foi que para a mulher

Tabela 2: Posturas no plano frontal.

\begin{tabular}{|l|l|l|}
\hline SEGMENTOS CORPORAIS & \multicolumn{1}{|c|}{ POSTURA ASSUMIDA } & \multicolumn{1}{c|}{ ATIVIDADES } \\
\hline Cabeça & $0^{\circ}$ & Visualização dos objetos e sustentação \\
\hline Tronco & $0^{\circ}$ a $81^{\circ}$ & Movimentação e sustentação \\
\hline Ombro direito & $0^{\circ}$ & $\begin{array}{l}\text { Sustentação, variação apenas na colocação dos feixes } \\
\text { embalados na caixa verde }\end{array}$ \\
\hline Ombro esquerdo & $0^{\circ}$ a $150^{\circ}$ & $\begin{array}{l}\text { Sustentação e movimentação: pegar e transportar os } \\
\text { feixes de tubos no apoio e caixas }\end{array}$ \\
\hline
\end{tabular}


Figura 13: Movimentação dos tubos.

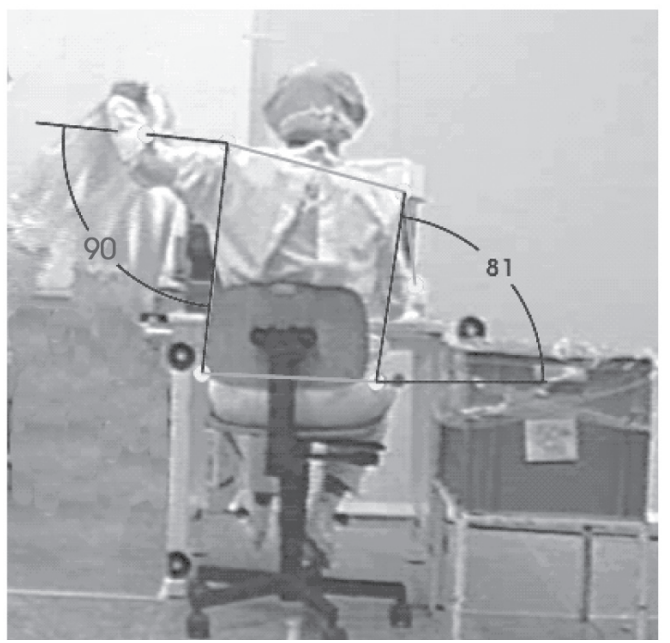

percentil 95, o posto de trabalho proporcionava uma maior rigidez postural (não permitia alternância na postura) principalmente para os membros inferiores e para aumentar a sua mobilidade, ela normalmente tinha que afastar a cadeira da mesa, aumentando ainda mais seus alcances frontais e laterais durante as operações de montagem, ocasionando a adoção de posturas de maior sobrecarga, tanto para a coluna vertebral como para os
Figura 14: Movimentação da caixa com as pinças.

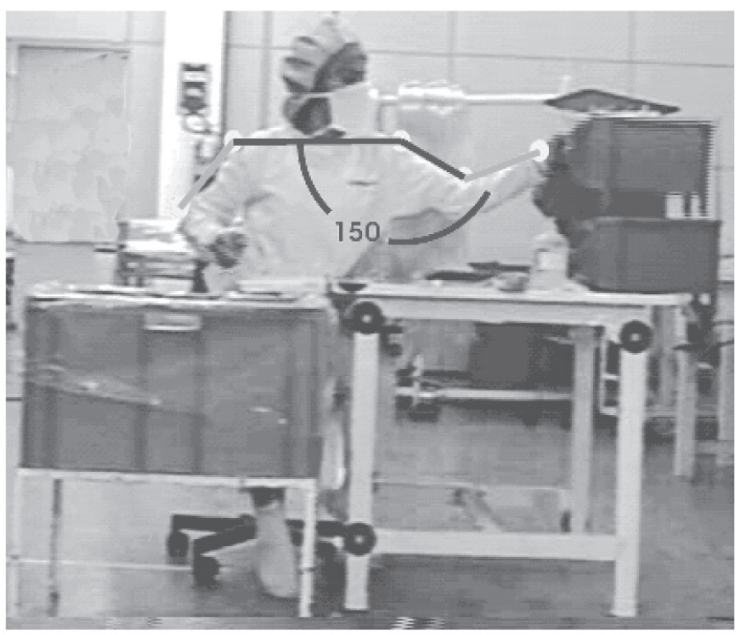

ombros. Demonstrava desta forma, que o posto também não estava adequado a ela.

Analisando a Tabela 1 e observando as Figuras 8, 9, 10, 11, 12 :

- Para o ângulo postural da cabeça da mulher percentil 5, observamos que normalmente ele está extremamente distante dos ângulos de conforto para as articulações da coluna cervical que é de cerca de $17^{\circ}$ a $29^{\circ}$. Chaffin and andersson

Tabela 3: Posturas no plano transversal

\begin{tabular}{|l|l|l|}
\hline SEGMENTOS CORPORAIS & \multicolumn{1}{|c|}{ POSTURA ASSUMIDA } & \multicolumn{1}{c|}{ ATIVIDADES } \\
\hline Cabeça & $0^{\circ}$ a $26^{\circ}$ & Visualização e sustentação \\
\hline Tronco & $0^{\circ}$ a $118^{\circ}$ & Sustentação e movimentação de objetos distantes \\
\hline Ombro direito & $0^{\circ}$ & Sustentação \\
\hline Ombro esquerdo & $0^{\circ}$ a $100^{\circ}$ & Sustentação e movimentação de objetos distantes \\
\hline
\end{tabular}

Figura 15: Movimentação da caixa com as pinças.

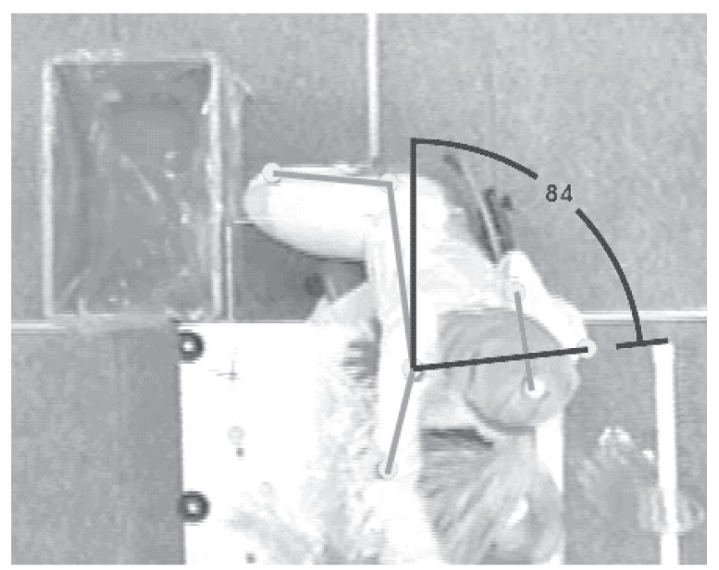

Figura 16: Movimentação dos tubos.

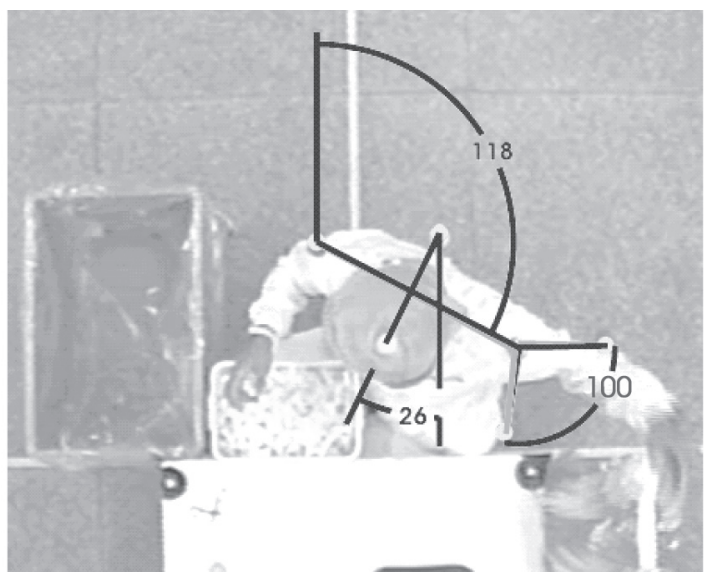


(1999) recomenda uma inclinação da cabeça em relação ao tronco de $20^{\circ}$ a $30^{\circ}$ e salienta que o desconforto aumenta muito a partir dessa última. Pheasant (1986) recomenda uma inclinação de $15^{\circ}$. A angulação em flexão, principalmente em atividade estática, leva a fadiga crescente da musculatura extensora do pescoço.

- Para o ângulo do tronco observamos também um afastamento dos ângulos de conforto principalmente nas atividades de movimentação das partes dos equipamentos para as montagens e preparar o cintamento. Os ângulos de conforto para esse segmento são: Grandjean (1981) recomenda $7^{\circ}$ a $9^{\circ}$; Chaffin and ANDERSSON (1999) recomenda uma inclinação de no máximo $20^{\circ}$. Esse afastamento normalmente envolve o aumento do braço de resistência do peso corporal em conjunto com os objetos manuseados o que leva a um maior esforço por parte da musculatura lombar.

- Para o ângulo do ombro observamos que em algumas situações, principalmente ao movimentar objetos distantes, a mulher percentil 5 excede o ângulo de $90^{\circ}$. Sabe-se que, a partir dessa angulação, as estruturas tendinosas tendem a sofrer um processo maior de compressão, principalmente o tendão do músculo supraespinhal e cabeça longa do bíceps braquial. Também a força muscular do músculo deltóide anterior passa a exercer uma componente de força de translação que empurra a cabeça do úmero na direção posterior da cavidade glenóide, região de menor concavidade, aumentando a instabilidade e forçando a uma maior atuação dos elementos ligamentares. (HAMMIL and KNUTZEN, 2000);

- Para o ângulo do cotovelo observamos uma maior flexão dessa articulação, com ângulos inferiores ao proposto que seriam de $80^{\circ}$ a $120^{\circ}$ (GRANDJEAN, 1981). Essa maior flexão pode levar ao encurtamento dos músculos flexores e a perda de força dessa musculatura.

A Tabela 2 e as figuras 13 e 14 apresentam os ângulos da articulação do ombro no plano frontal em ângulos próximo ou acima de $90^{\circ}$, o que não é recomendado para essa articulação principalmente quando associada a manuseio de carga, pois aumenta a sobrecarga nas estruturas do ombro, proporciona maior compressão tendinosa (músculo supra-espinhal e porção longa do bíceps braquial) e a uma maior instabilidade na região posterior da cavidade glenóide, sobrecarregando a parte ligamentar (HAMMILL and KNUTZEN, 2000).

A Tabela 3 e as Figuras 15 e 16 apresentam situações freqüentes durante as atividades de montagem principalmente nas situações que envolvem movimentação de objetos e tubos distantes. Observamos rotações de tronco combinadas com deslocamentos do membro superior em grande amplitude. As rotações do tronco não são recomendadas, pois representam uma grande sobrecarga para os discos intervertebrais, que já se encontram em maior compressão pela postura sentada. As rotações de tronco provocam um movimento na direção contrária às fibras que compõem o anel fibroso, podendo levar ao seu estiramento e rompimento, sendo as causas mais freqüentes do herniamento discal nessa região (HAMMILL and KNUTZEN, 2000).

Podemos, então, concluir das análises posturais que a atividade de montagem de equipamentos de infusão apresenta inúmeros problemas posturais decorrentes da inadequação do posto de trabalho à atividade realizada. Dentro dos modelos de riscos biomecânicos apresentados para os DORT, o fator postural é sempre pontuado como um fator de risco primário, o que se constatou ocorrer com grande incidência nessa atividade.

Através dos modelos biomecânicos e demais funções disponíveis no programa BIOMEC foi também possível calcular as frequiências de manipulação e a freqüência das operações. Pelos cálculos, as freqüências de manipulação das montagens apresentam-se muito elevadas, na ordem de 1 equipo em 13,5 seg, cerca de 266 equipamentos por hora, com produção diária estimada de 1.800 equipamentos. Para cada equipo cerca de cinco operações básicas são realizadas. $\mathrm{Na}$ Tabela 4 são apresentados os tempos médios para cada operação.

A coluna lombar também foi pontuada como área de desconforto, isso ocorre devido principalmente à sustentação do peso da parte superior do corpo, sobrecarregada pelo manuseio de cargas e por movimentos de rotação freqüentes em postura sentada prolongada.

As características das peças, seu manuseio e sua inserção definem as dificuldades e os riscos para o montador. Algumas condições devem ser atendidas para que as peças sejam corretamente montadas. As dificuldades analisadas estão associadas aos seguintes fatores: visão restrita, falta de espaço para as mãos e ferramentas, peças pesadas, afiadas, escorregadias, flexíveis e frágeis e situações de dimensionamento do

Tabela 4: Tempos calculados das operações de montagem.

\begin{tabular}{|l|c|}
\hline \multicolumn{1}{|c|}{ SEQÜÊNCIAS } & TEMPOS MÉDIOS \\
\hline Inserindo Flashball & $1,727 \mathrm{~s}$ \\
\hline Inserindo o intermediário & $1,331 \mathrm{~s}$ \\
\hline Posicionando a pinça & $1,947 \mathrm{~s}$ \\
\hline Inserindo a câmara & $1,727 \mathrm{~s}$ \\
\hline Cintamento/ensacamento & $3,330 \mathrm{~s}$ \\
\hline
\end{tabular}


posto que promovam a adoção de posturas lesivas ao trabalhador.

Este artigo é dirigido à identificação dos problemas biomecânicos que podem ocorrer em postos de trabalho de montagem. A partir deste trabalho é possível evidenciar que, com o sistema de videocinematografia BIOMEC, a análise dos parâmetros biomecânicos, cinemáticos e a dos parâmetros de sobrecargas articulares (através dos modelos biomecânicos), permite uma alternativa aos sistemas de análise de riscos biomecânicos com base apenas na observação. A vantagem da abordagem proposta pelo sistema está na facilidade e precisão dos cálculos dos parâmetros biomecânicos e na sua aplicação imediata na correção, seja na postura ou na dinâmica do trabalho em análise, bem como na geração de recomendações para projetos de novos postos de trabalho para esse tipo de montagem manual.

Ressalte-se que a intervenção ergonômica deve sempre ser feita através de uma abordagem integrada entre o projeto do produto, o projeto do posto de trabalho e o planejamento do processo (arranjo organizacional) pelo qual o mesmo será produzido. O processo e a organização do trabalho irão definir as pausas de trabalho, a rotação das tarefas e os trabalhos em grupo. As conseqüências desse estudo na empresa analisada resultaram em modificações no produto e no projeto de um novo posto de trabalho para os equipamentos estudados, nos quais os fatores de risco biomecânicos foram minimizados.

Este estudo é parte integrante do trabalho de tese que o segundo autor desenvolveu no Programa de Engenharia de Produção da COPPE/UFRJ e se insere nas linhas de pesquisa do GEPRO - Grupo de Ensino e Pesquisa em Gestão Integrada de Projeto de Produtos Industriais.

\section{Artigo recebido em 06/12/2001 \\ Revisado em 05/12/2002 \\ Aprovado para publicação em 12/02/2003}

\section{- Referências Bibliográficas}

CHAFFIN, D.B., ANDERSSON, G.B.J. and MARTIN, B.J., Occupational Biomechanics, ed. John Wiley \& Sons, New York, 1999.

DRURY, C.G. A biomechanical evaluation of the repetitive motion injury potential of industrial jobs, Seminar in Occupational Medicine, 2, 41-49, 1987.

GARG, A. and MOORE, J. S. The stain index: a method to analyse jobs for risk of distal upper disorders, Proceedings of $13^{\text {th }}$ Triennial Congress of International Ergonomics Association, Tampere, Finland, 40-42, 1997.

GRANDJEAN, E. Sitting Posture, Proceedings of the Symposium, ed. Taylor $\&$ Francis, London, 1978

HAGBERG, M., SILVERSTEIN, B., WELLS,R., SMITH, M., HENDRICK, H.W., CARAYON, P. and PÉRUSSE, M. Work related musculoskeletal disorders (WMSDs): a reference book for prevention, ed. Taylor \& Francis, London, 22, 1995
HAMMILL, J., KNUTZEN, K., Bases biomecânicas do Movimento Humano, ed. Manole, São Paulo, 2000.

KEMMLERT, K. A method assign for the identification of ergonomic hazard PLIBEL, Applied Ergonomics, 26(3), 199211, 1995.

KRUIZINGA, C.P., DELLEMAN, N.J. AND SCHELLEKENS, J.M.H. Prediction of musculoskeletal discomfort in a pick and place task (a pilot study), International Journal of Occupational Safety and Ergonomics, 4(3), 271-286, 1998.

LIMA, M.E.A., DE ARAÚJO, J.N.G. e LIMA, F.P.A.L.E.R - Lesões por Esforços Repetitivos - Dimensões Ergonômicas e Psicossociais, ed. Health, Belo Horizonte, MG, 11-24, 1998.

McATAMNEY, L. and CORLETT, E.N. RULA - a survey method for the investigation of work related upper limb disorders, Applied Ergonomics, 24(2), 9199.
NAVEIRO, R.M. Montagem Robotizada In: Robótica industrial, aplicação na indústria de manufatura $e$ de processos, ed. Vitor Ferreira Romano, ed. Edgard Blücher Ltda., São Paulo, 2002.

NAVEIRO, R. \& OLIVEIRA V. 0 projeto de engenharia, arquitetura e desenho industrial. Ed. Universidade Federal de Juiz de Fora, Juiz de Fora, 2001.

PHEASANT, S. Body space, Taylor \& Francis, London, 1986.

PUTZ-ANDERSSON, V. Cumulative Trauma Disorders : A Manual for Musculoskeletal diseases of the Upper Limb, ed. Taylor \& Francis, New York, 1988.

SCHOENMARKLIN, R., MARRAS, W.W. and LEURGANS, S.E. Industrial wrist motions and incidence of hand/wrist cumulative trauma disorders, Ergonomics, 37, 1449-1459, 1994.
SILVERSTEIN, B. The use of checklists for upper limb risk assessment, Proceedings of $13^{\text {th }}$ Triennial Congress of International Ergonomics Association, Tampere, Finland, 109111, 1997.

TANAKA, J. and MCGLOTHIN, J.D. A conceptual model for prevention of work related carpal tunnel syndrome, Intern. J. Ind. Ergon, 11, 181-193, 1993.

TICHAUER, E.R. Biomechanics Basis of Ergonomics, ed. John Wiley \& Sons, New York, 1978.

WINKEL, J. and WESTGAARD, H. A mode for solving work related musculoskeletal problems in a profitable way, Applied Ergonomics, 27(2), 71-77, 1996.

WINKEL, J. and WESTGAARD, H. Occupational and risk factor shoulderneck complains: Part I - guidelines for practioner, Intern. J. Ind. Ergon., 10, 7983,1992 . 